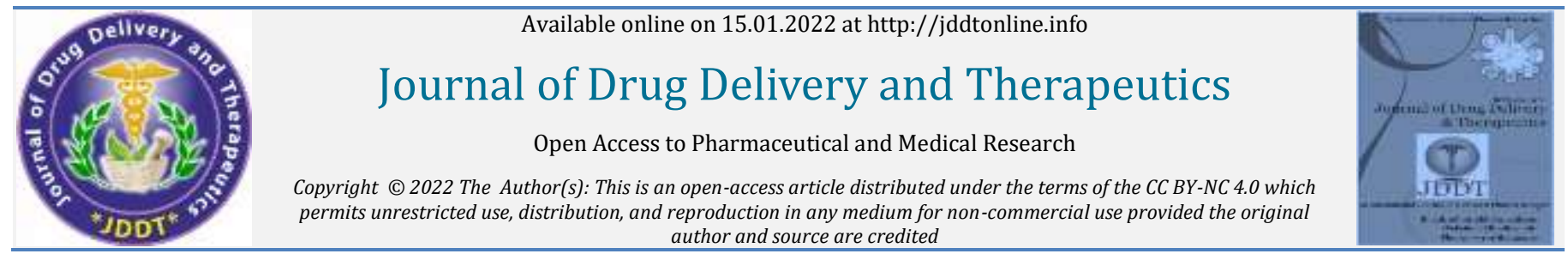

Copyright (c) 2022 The Author(s): This is an open-access article distributed under the terms of the CC BY-NC 4.0 which author and source are credited

Research Article

\title{
Spectrum of Biopsy Proven Primary Tubulointerstitial Diseases of the Kidney: A Single Centre Study
}

\author{
Wani Asif Sadiq ${ }^{1,2}$, Zahir Zafirah ${ }^{3,4}$, Krishnani Narendra ${ }^{5}$ \\ ${ }^{1}$ DM Nephrology, Department Of Nephrology and Renal Transplantation, Sanjay Gandhi Post Graduate Institute of Medical Sciences, Lucknow, Uttar \\ Pradesh, India \\ 2 Presently working as Consultant Nephrologist at Government Medical College Srinagar, J\&K, India \\ ${ }^{3}$ PDCC Renal Pathology, Department of Pathology, Sanjay Gandhi Post Graduate Institute of Medical Sciences, Lucknow, Uttar Pradesh, India \\ ${ }^{4}$ Presently working as Consultant Pathologist at Government Medical College Srinagar, J\&K, India \\ ${ }^{5}$ MD Pathology, Department of Pathology, Sanjay Gandhi Post Graduate Institute of Medical Sciences, Lucknow, Uttar Pradesh, India
}

\section{Article Info:}

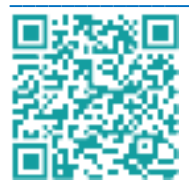

Article History:

Received 21 December 2021 Reviewed 02 January 2022 Accepted 07 January 2022 Published 15 January 2022

Cite this article as:

Wani AS, Zahir Z, Krishnani N, Spectrum of Biopsy Proven Primary Tubulointerstitial Diseases of the Kidney: A Single Centre Study, Journal of Drug Delivery and Therapeutics. 2022; 12(1):129-132

DOI: http://dx.doi.org/10.22270/jddt.v12i1.5290

\section{*Address for Correspondence:}

Zafirah Zahir, Department of Pathology, Govt Medical College Srinagar, J\&K, India

\section{Abstract}

Background: The tubulointerstitial diseases can be due to a wide variety of etologies and mechanisms which vary with age, race and geographical area. In this study we aim to study the clinicopathological spectrum of biopsy proven primary tubulointerstitial diseases among patients in North India.

Methods: This is a 5 year retrospective, single centre cohort, observational study.The data base was searched to identify all patients with primary tubulointerstitial diseases in their native kidney biopsies.

Results: A total of 3091 renal biopsies were studied of which 283 were primary tubulointerstitial diseases. The mean age of patients was $43.2( \pm 14.6)$ years. Most of the patients were males with acute kidney injury as the most common presentation. Tubulointerstitial nephritis was the most common disease occurring in 126 patients. Acute interstitial nephritis was seen in 81 patients and chronic interstitial nephritis was seen in 45 patients. Granulomatous interstitial nephritis was seen in 27 patients. There were four patients of pigment nephropathy, 83 cases of acute tubular necrosis and 19 cases of cast nephropathy.

Conclusion: Primary tubulointerstitial diseases comprise about $9.1 \%$ of the total cases Tubulointerstitial nephritis is the most common diagnosis in these patients. Tuberculosis is still a leading cause of granulomatous interstitial nephritis in our country followed by fungal etiology. Acute cortical necrosis affects mostly females post obstretric complications in our setup. Given the enemic nature of malaria in India, G-6PD deficiency is an important differential in patients presenting with pigment nephropathy.

Keywords: Biopsy, Tubulointerstitial Diseases of the Kidney, Tuberculosis, Acute cortical necrosis

\section{INTRODUCTION}

The diseases of the kidney can be broadly classified into glomerular, tubulointerstitial or vascular diseases. The tubulointerstitial compartment comprise most $(\sim 80 \%)$ of the renal volume and its diseases can be primary as a result of primary injury to this region or secondary as a part of secondary changes to other regions of the kidney. The tubulointerstitial diseases can be due to a wide variety of etologies and pathogenic mechanisms. The incidence of various tubulointerstitial diseases shows variation with respect to age, race, geographical area, inclusion criteria, and even the mode of diagnosis ${ }^{1}$. There are a very few studies available on the spectrum of tubulointerstitial diseases in our country. In this study we aim to study the clinicopathological spectrum of biopsy proven primary tubulointerstitial diseases among patients in North India.

\section{METHODS}

\section{STUDY DESIGN, SETTING AND PARTICIPANTS}

This is a 5 year retrospective, single centre cohort, observational study (June 2016 to June 2021) conducted at Sanjay Gandhi Post-Graduate Institute of Medical Sciences, India.The data base of the hospital was searched to identify all patients with their native kidney biopsies. The primary tubulointerstitial renal diseases were included in the analysis.

EXCLUSION CRITERIA: We excluded patients without histologic diagnosis (inadequate biopsies), with secondary tubulointerstitial changes, repeat biopsies and transplant renal biopsies.

\section{RENAL BIOPSY EVALUATION}

Three core biopsies were taken under ultrasound guidance, one for light microscopy, immunofluorescence and electron microscopy. Standard processing techniques were followed in 
all the biopsies. Recorded immunofluorescence findings included the strength of staining for IgG, IgM, IgA, C3, C1q, kappa and lambda; graded on a 1 to 4 semiquantitative scale. Each biopsy was diagnosed according to the standard definitions and criteria using light microscopy, immunofluorescence, and electron microscopy wherever necessary.

\section{DATA SOURCE AND VARIABLES}

Clinical data, laboratory data and follow up records of the patients were retrieved from the hospital information system. The treatment received by the patients was noted from the treatment charts.

Patients $\leq 18$ years of age were regarded as children.

Acute kidney injury (AKI) was defined as an abrupt decrease in renal function occurring within 7 days. Acute Kidney Disease (AKD) was defined as an acute or subacute loss of kidney function between 7 and 90 days after an AKI insult and chronic kidney disease (CKD) was defined as kidney function impairment persisting $>90$ days $^{2}$. The estimated glomerular filtration rate was calculated by the Chronic Kidney Disease Epidemiology Collaboration equation and expressed as mililitres per minute per $1.73 \mathrm{~m}^{3}$. AKI was classified according to AKIN staging system in three stages: AKIN Stage 1-Serum creatinine increase $\geq 26.5 \mu \mathrm{mol} / \mathrm{l}(\geq 0.3 \mathrm{mg} / \mathrm{dl}$ ) or increase to 1.5-2.0-fold from baseline, AKIN Stage 2- Serum creatinine increase >2.0-3.0-fold from baseline and AKIN Stage 3-Serum creatinine increase $>3.0$-fold from baseline or serum creatinine $\geq 354 \mu \mathrm{mol} / \mathrm{l}(\geq 4.0 \mathrm{mg} / \mathrm{dl}$ ) with an acute increase of at least $44 \mu \mathrm{mol} / \mathrm{l}(0.5 \mathrm{mg} / \mathrm{dl})$ or need for renal replacement therapy 4 . Oliguria was defined as urinary output of $<400 \mathrm{ml} / 24$ hrs while anuria was defined as urinary output of $<100 \mathrm{ml} / 24$ hrs. Microscopic hematuria was defined as at least 5 red cells per high-power field on microscopic examination or positive blood by urine dipstick. Leukocytosis was defined as leukocytes $>10.5 \times 10^{9} / \mathrm{L}$, eosinophilia as eosinophils $>0.5 \mathrm{x}$ $10^{9} / \mathrm{L}$, and eosinophiluria as urine eosinophils $>1 \% 5$.

Advanced renal failure was used for patients fulfilling any of the following KDIGO AKI stage 3 criteria: increase in serum creatinine to $>4.0 \mathrm{mg} / \mathrm{dl}$, initiation of renal replacement therapy or decrease in eGFR to $<35 \mathrm{ml} / \mathrm{min}$ per $1.73 \mathrm{~m}^{6}$.

ESRD was defined as a decrement in the patient's kidney function to a level at which either long-term dialysis or kidney transplantation is required to sustain life 7 . Chronic kidney disease (CKD) was defined as kidney damage or glomerular filtration rate (GFR) $<60 \mathrm{~mL} / \mathrm{min} / 1.73 \mathrm{~m} 2$ for 3 months or more. eGFR was calculated using the updated Schwartz equation ${ }^{8}$.

\section{FOLLOW-UP}

The follow-up period was considered to be the time interval between renal biopsy and the last outpatient visit, death, or kidney failure, whichever happened earlier.

\section{STATISTICAL ANALYSIS}

The statistical analysis was done using SPSS Version 23.0 (IBM Corp., Armonk, NY, USA). Categorical variables expressed as numbers or percentages were compared using Chi Square and Fisher's exact test (as applicable). Continuous variables reported as mean or median (depending on the normality of data), were compared using Wilcoxon rank-sum methods.

Ethics approval and consent: This was not sought as it was a retrospective study and did not involve any active participation of the patients. The patients whose data was analysed could also not be contacted further. Many patients were de-identified and waiver of their consent did not adversely affect the rights and welfare of the participants.

\section{RESULTS}

\section{CLINICAL FEATURES}

A total of 3091 renal biopsies were studied of which 283 were primary tubulointerstitial diseases. The mean age of patients was $43.2( \pm 14.6)$ years. Most of the patients were males with male:female ratio 2.7:1 except for acute cortical necrosis where most of the patients were females. Most common presentatation was acute kidney injury (stage 3). Most of the patients $245(86.5 \%)$ had nil or mild proteinuria only. Microscopic hematuria was seen in 82 (28.9\%) patients. Oliguria was seen in $133(46.9 \%)$ patients and anuria in 56 $(19.7 \%)$ patients. Peripheral eosinophilia was present in only in $20(32.7 \%)$ patients

\section{PATHO-HISTOLOGICAL DIAGNOSIS}

The patho-histological spectrum of primary tubulointerstitial diseases is shown in Table1. Tubulointerstitial nephritis was the most common disease occurring in 126 patients. Acute interstitial nephritis was seen in 81 patients and chronic interstitial nephritis was seen in 45 patients. The most common cause of acute interstitial nephritis was drugs and for chronic interstitial nephritis it was idiopathic. Granulomatous interstitial nephritis was seen in 27 patients. Tuberculosis was the commonest cause in our granulomatous nephritis patients. Funal infections were seen in 08 patients of which mucomycosis was seen in three, aspergillosis in two, cryptococcal in two and candida in one. There were four patients of pigment nephropathy, 83 cases of acute tubular necrosis and 19 cases of cast nephropathy.

TABLE 1: Showing Spectrum Of Primary Tubulointerstitial Diseases In Our Population.

\begin{tabular}{|l|l|l|l|}
\hline Tubulointerstitial & ATN & 83 & \\
\cline { 2 - 4 } Diseases & TIN & Acute & 81 \\
\cline { 2 - 4 } & Chronic & 45 \\
\cline { 2 - 4 } & ACN & 41 & \\
\cline { 2 - 4 } & $\begin{array}{l}\text { Cast } \\
\text { Nephropathy }\end{array}$ & 19 & \\
\cline { 2 - 4 } & $\begin{array}{l}\text { Oxalate } \\
\text { Nephropathy }\end{array}$ & 02 & \\
\cline { 2 - 4 } & $\begin{array}{l}\text { Pigment } \\
\text { Nephropathy }\end{array}$ & 04 & \\
\hline
\end{tabular}

\section{FOLLOW-UP}

Most children were on regular follow-up. A total of 198 (69.9\%) improved and were discharged from follow-up, 69 (24.3\%) progressed to chronic renal failure and $16(5.6 \%)$ were lost to follow-up. All patients who were lost to follow-up were children from remote areas or had financial constraints.

\section{DISCUSSION}

There is scarcity of data about the tubulointerstitial diseases in India due to unavailability of renal biopsy registry ${ }^{9}$. In this study we aim to study the clinicopathological spectrum of biopsy proven tubulointerstitial diseases where it is the primary target of pathogenic process rather than being involved secondarily.

Tubulointerstitial nephritis (TIN) constituted $44.5 \%$ of the patients. Acute insterstitial nephritis (AIN) constituted 28.6\% of the patients while $15.9 \%$ of the cases. In an autopsy series the incidence of acute TIN was $1.7 \%$ and chronic TIN was $0.2 \%$ of all the renal diseases ${ }^{10}$. In a study conducted by 
Farrington etal out of all the patients presenting with unexplained renal failure, the most common histological lesion was interstitial nephritis in $33 \%$ patients ${ }^{11}$. The most common etiology in our study was drug induced AIN. Drugs were the major causes of AIN in other studies as well ${ }^{12}$.

Granulomatous TIN (GIN) accounted for 9.5\% of the tubulointerstitial diseases in our study and $0.8 \%$ of all the renal diseases. GIN is a rare histological diagnosis with overall incidence of $<1 \%$ in most of the studies ${ }^{13,14,15}$. It accounted for about $6 \%$ of all the tubulointerstitial nephritis ${ }^{16}$.

Studies from the west have shown sarcoidosis, drugs and idiopathic etiology as the most common causes of granulomatous interstitial nephritis ${ }^{17}$ whereas tubercular and fungal infections are still important causes of GIN in developing countries ${ }^{18}$.

In our study tuberculosis was the most common cause of granulomas in our study. Fungal infections were seen in eight patients $(2.8 \%)$. They constitute $29.6 \%$ of granulomatous interstitial nephritis. There were two patients of Cryptococcus who were immunocompromised due to HIV infection. Three patients of mucomycosis and a single patient of Candida had diabetes as comorbidity. In other studies as well fungal GIN due to Histoplasma, Candida and Cryptococcus have been found mostly in immunocompromised patients ${ }^{13}$.

Acute tubular necrosis was the second most common pathohistological diagnosis accounting for $29.3 \%$ of the cases. The real incidence of these cases is much higher as all the cases of acute renal failure are not biopsied.

Acute cortical necrosis (ACN) comprised of $14.4 \%$ of the primary tubulointerstitial diseases. The incidence of ACN has gone down in developed countries whereas it is still found in $5 \%-7 \%$ of the patients in developing countries ${ }^{20}$. One of the main reasons is obstetric related complications in developing countries. In contrast to other diseases ACN mostly affected females in our study (87.8\%). The most common cause in our patients was also obstretric complications. Obstetric causes were the most common causes of acute cortical necrosis in other Indian studies as well. Chugh etal in their study reported that acute cortical necrosis post obstetric occurred in $56.6 \%$ patients and nonobstetric causes were responsible in rest $43.4 \%$ of patients ${ }^{21}$.

Three of the four patients with pigment nephropathy were G6-PD deficient and developed hemolysis after admission of anti-malarial drug (chloroquine). One of the patient had rhabdomyolysis after strenuous exercise. In a study conducted by Sakthirajan etal rhabdomyolysis was the most common cause of pigment cast nephropathy. However in India, where malaria is endemic, G-6-PD deficiency causing hemolysis after anti-malarial drugs is also an important cause of pigment nephropathy and should always be kept in the differential diagnosis 22

The biggest limitation of this study was the retrospective nature of the study. Our strengths were the large number of cases studied, extensive workup in almost all the cases and a well maintained hospital record system.

We conclude that biopsy proven primary tubulointerstitial diseases comprise about $9.1 \%$ of the total cases and mostly affects males. Tubulointerstitial nephritis is the most common pathohistological diagnosis in these patients. Tuberculosis is still a leading cause of granulomatous interstitial nephritis in our country followed by fungal etiology. Acute cortical necrosis affects mostly females post obstretric complications in our setup. Given the endemic nature of malaria in India, G6PD deficiency is an important differential in patients presenting with pigment nephropathy.
Acknowledgement: NIL

Funding: NIL

Conflicts of Interest: NIL

\section{REFERENCES}

1. Rastegar A, Kashgarian M. The clinical spectrum of tubulointerstitial nephritis. Kidney Int. 1998; 54(2):313-27. https://doi.org/10.1046/j.1523-1755.1998.00001.x

2. Khwaja A. KDIGO clinical practice guidelines for acute kidney injury. Nephron 2012; 120:c179-c184. https://doi.org/10.1159/000339789

3. Levey AS, Stevens LA, Schmid CH et al. A new equation to estimate glomerular filtration rate. Ann Intern Med 2009; 150:604-612. https://doi.org/10.7326/0003-4819-150-9-200905050-00006

4. Ricci Z, Cruz D N, and Ronco C. Classification and staging of acute kidney injury: beyond the RIFLE and AKIN criteria. Nature Reviews Nephrology 2011; 7(4):201 208. https://doi.org/10.1038/nrneph.2011.14

5. Muriithi AK, Leung N, Valeri AM, Cornell LD, Sethi S, Fidler ME and H. Nasr SH. Clinical characteristics, causes and outcomes of acute interstitial nephritis in the elderly. Kidney International 2015; 87:458-464. https://doi.org/10.1038/ki.2014.294

6. Section 2: AKI Definition. Kidney Int Suppl 2011; 2(1):19-36. https://doi.org/10.1038/kisup.2011.32

7. Agarwal R. Defining end-stage renal disease in clinical trials: a framework for adjudication. Nephrol Dial Transplant 2015; 31:864-867 https://doi.org/10.1093/ndt/gfv289

8. Mian AN and Schwartz GJ. Measurement and Estimation of Glomerular Filtration Rate in Children. Adv Chronic Kidney Dis 2017; 24(6):348-356 https://doi.org/10.1053/j.ackd.2017.09.011

9. Rajapurkar MM, John GT, Kirpalani AL et al. What do we know about chronic kidney disease in India: First report of the Indian CKD registry. BMC Nephrol. 2012; 13:10. https://doi.org/10.1186/1471-2369-13-10

10. Zollinger HU, Mihatsch MJ: Renal Pathology in Biopsy. Berlin, Springer-Verlas, 1978, pp 407-410. https://doi.org/10.1007/9783-642-66731-2_20

11. Farrington K, Levison DA, Greenwood RN, Cattell WR, Baker LR. Renal biopsy in patients with unexplained renal impairment and normal kidney size. Q J Med. 1989 Mar; 70(263):221-33.

12. Muriithi AK, Leung N, Valeri AM, Cornell LD, Sethi S, Fidler ME, Nasr SH. Biopsy-proven acute interstitial nephritis, 1993-2011: a case series. Am J Kidney Dis. 2014 Oct; 64(4):558-66. https://doi.org/10.1053/j.ajkd.2014.04.027

13. Ogura M, Kagami S, Nakao M, Kono M, Kanetsuna Y, Hosoya T. Fungal granulomatous interstitial nephritis presenting as acute kidney injury diagnosed by renal histology including PCR assay. Clin Kidney J. 2012; 5(5):459-462. https://doi.org/10.1093/ckj/sfs103

14. Colvin RB, Traum AZ, Taheri D et al. Granulomatous interstitial nephritis as a manifestation of Crohn disease. Arch Pathol Lab Med 2014; 138:125-127. https://doi.org/10.5858/arpa.20120224-CR

15. Joss N, Morris S, Young B et al. Granulomatous interstitial nephritis. Clin J Am Soc Nephrol 2007; 2:222-230. https://doi.org/10.2215/CJN.01790506

16. Viero RM, Cavallo T. Granulomatous interstitial nephritis.Hum Pathol 1995; 26:1347-1353. https://doi.org/10.1016/00468177(95)90300-3

17. Agrawal V, Kaul A, Prasad N, Sharma K, Agarwal V. Etiological diagnosis of granulomatous tubulointerstitial nephritis in the tropics. Clin Kidney J. 2015 Oct; 8(5):524-30. https://doi.org/10.1093/ckj/sfv071

18. Nasr SH, Shanafelt TD, Hanson CA, Fidler ME, Cornell LD, Sethi S, Chaffee KG, Morri J, Leung N. Granulomatous interstitial nephritis 
secondary to chronic lymphocytic leukemia/small lymphocytic lymphoma. Ann Diagn Pathol. 2015; 19(3):130-6.

https://doi.org/10.1016/j.anndiagpath.2015.03.003

19. Ogura M, Kagami S, Nakao M, Kono M, Kanetsuna Y, Hosoya T. Fungal granulomatous interstitial nephritis presenting as acute kidney injury diagnosed by renal histology including PCR assay. Clin Kidney J. 2012 Oct; 5(5):459-462. https://doi.org/10.1093/ckj/sfs103

20. Bhaduaria D, Kaul A, Lal H, Mishra P, Jain M, Prasad N, Pradhan M, Patel MR, Gupta A, Sharma RK. Acute cortical necrosis in pregnancy still an important cause for end-stage renal disease in developing countries. Saudi J Kidney Dis Transpl 2019; 30:325-33. https://doi.org/10.4103/1319-2442.256839

21. Chugh KS, Jha V, Sakhuja V, Joshi K. Acute renal cortical necrosis--a study of 113 patients. Ren Fail. 1994; 16(1):37-47. https://doi.org/10.3109/08860229409044846

22. Sakthirajan R, Dhanapriya J, Varghese A, Saravanakumar K, Dineshkumar T, Balasubramaniyan T, Gopalakrishnan N, Abraham Kurien A. Clinical profile and outcome of pigment-induced nephropathy. Clin Kidney J. 2018 Jun; 11(3):348-352. https://doi.org/10.1093/ckj/sfx121 